\title{
Nanomaterials in the Environment: Perspectives on in Vivo Terrestrial Toxicity Testing
}

\author{
Monique C. P. Mendonça ${ }^{1 *}$, Cintia Rizoli ${ }^{1}$, Daiana S. Ávila ${ }^{2}$, Mónica J. B. Amorim ${ }^{3}$ and \\ Marcelo B. de Jesus ${ }^{1 *}$ \\ ${ }^{1}$ Department of Biochemistry and Tissue Biology, Institute of Biology, University of Campinas, Campinas, Brazil, ${ }^{2}$ Federal \\ University of Pampa, Uruguaiana, Brazil, ${ }^{3}$ Department of Biology and CESAM, University of Aveiro, Aveiro, Portugal
}

\section{OPEN ACCESS}

Edited by:

Md Ahmaruzzaman,

National Institute of Technology,

Silchar, India

Reviewed by:

Sema Salgin,

Cumhuriyet University, Turkey

Noor Aman Ahrar Mundari,

B. S. Abdur Rahman University, India

*Correspondence: Monique C. P. Mendonça

mo_padilha@hotmail.com

Marcelo B. de Jesus

dejesus@unicamp.br

Specialty section:

This article was submitted to Green and Environmental Chemistry, a section of the journal

Frontiers in Environmental Science

Received: 30 August 2017 Accepted: 13 October 2017

Published: 27 October 2017

Citation: Mendonça MCP, Rizoli C, Ávila DS, Amorim MJB and de Jesus MB (2017)

Nanomaterials in the Environment:

Perspectives on in Vivo Terrestrial Toxicity Testing

Front. Environ. Sci. 5:71.

doi: 10.3389/fenvs.2017.00071
Over the last decade, engineered nanomaterials (NMs) brought a revolutionary development in many sectors of human life including electronics, paints, textiles, food, agriculture, and health care. However, the exponential growth in the number of NMs applications resulted in uncertainties regarding their environmental impacts. Currently, the common approach for assessing the toxicity of NMs such as, carbon-(fullerenes, single- and multi-walled carbon nanotubes), mineral-(gold and silver nanoparticles, cerium and zinc oxide, silicon and titanium dioxide), and organic-based NMs (dendrimers) includes standard guidelines applied to all chemical compounds. Nevertheless, NMs differ from traditional materials as their physicochemical and surface properties influence the toxic rather than their composition alone. Considering such NMs specificities, adaptations in some methods are necessary to ensure that environmental and human health risks are accurately investigated. In this context, the focus of this mini-review is to summarize the current knowledge in nanotoxicology regarding relevant organisms and experimental assays for assessing the terrestrial toxicity of NMs.

Keywords: Enchytraeus albidus, Caenorhabditis elegans, nanoparticles, nanotoxicity, standard guidelines

\section{INTRODUCTION}

Engineered nanomaterials (NMs) are defined by the International Organization for Standardization (ISO) as those intentionally produced to have specific purpose or function, with at least one external dimension, or presenting an internal or surface structure in the nanoscale $(\sim 1$ to $100 \mathrm{~nm}$ ) (ISO/TS $80004-1,2015)$. Due to their unique physicochemical properties, the production and use of these NMs are increasing exponentially in all sectors of human life, consequently, their amount released into the environment during all stages of their lifespan (production, use, and disposal).

Ecotoxicity testing of NMs is a challenge considering the lack of information related to fate, potential interactions, and behavior of the NMs in the surrounding environments. Furthermore, abiotic factors can influence specific physicochemical properties of NMs affecting their bioavailability and toxicity (El Badawy et al., 2010; Grillo et al., 2015). Thus, to ensure the reliability and reproducibility of ecotoxicity tests, NMs should be accurately characterized in multiple life cycle endpoints and the experimental parameters should be carefully chosen (Holden et al., 2016).

The Organization for Economic Cooperation and Development (OECD) has published several guidelines for assessing the potential effects of conventional chemicals on human health 
and environment ${ }^{1}$ Regarding NMs, the consensus in the scientific and regulatory communities is that many current health effects and ecotoxicology test guidelines (TG) for conventional chemicals apply to NMs. However, these TG need revision taking into account the specificities of the NMs and guidance on NMs preparation, delivery, and metrology need development for toxicity testing (OECD, 2009a; ECHA, 2014; Rasmussen et al., 2016).

The in vivo studies are still the gold standard to predict human toxicity. Nevertheless, following the $3 \mathrm{R}$ principle (Replacement, Reduction, and Refinement), the use of lower organism in the initial screening is recommended to replace and reduce the use of vertebrates test species. The purpose of the present mini-review is therefore to describe some of the more relevant organisms and protocols that have been used for terrestrial toxicity testing of NMs.

\section{CURRENT TERRESTRIAL TOXICITY TESTS}

Environmental hazard assessment in the terrestrial media can be performed using a suite of tests as standardized by OECD and ISO, an example update can be found in (Amorim et al., 2016). These tests are performed on animals that may be exposed directly or indirectly to the contaminated soil including microorganisms, soil invertebrates, and vertebrates. Among these models we, highlight the most often used models from lower organism to higher mammal models.

\section{Nematode Toxicity Studies: Caenorhabditis elegans}

Caenorhabditis elegans is abundant in ecosystems and plays a major role in the decomposition of soil organic matter and nutrient cycling. Many C. elegans characteristics are desirable for toxicological studies, such as small size (1 mm in length), optically transparency, readily propagation (generation time approximately 3 days), and simple anatomy (959 identified somatic cells in the adult, in addition to programmed cell death in others 131 cells during development; Brenner, 1974; Sulston et al., 1983). Hence, C. elegans can be used in different types of toxicological assays, including high-throughput screening, which is limited in more complex animals. Additionally, the complete sequence of C. elegans, finished in 2002, allows a full characterization of new genes and proteins those are relevant in mediating human diseases (C. elegans Sequencing Consortium, 1998). Many mutants have been generated, thus permitting the search for mechanistic toxicity. Furthermore, proteins can be tagged with green fluorescent protein (GFP), allowing the visualization of dopaminergic neurons, for example (Chalfie et al., 1994).

Several endpoints can be carried out to assess the toxic effects of chemicals on C. elegans (Figure 1). Worms can be exposed to NMs in different types of media such as, liquid (M9 buffer, saline, $\mathrm{K}$ or $\mathrm{S}$ medium), solid (nematode growth medium or OP50 medium), or directly in soil samples. The absorption of the chemicals occurs mainly through the mouth, whereas the thick

${ }^{1}$ http://www.oecd.org/chemicalsafety/testing/oecdguidelinesforthetestingofchemicals htm.

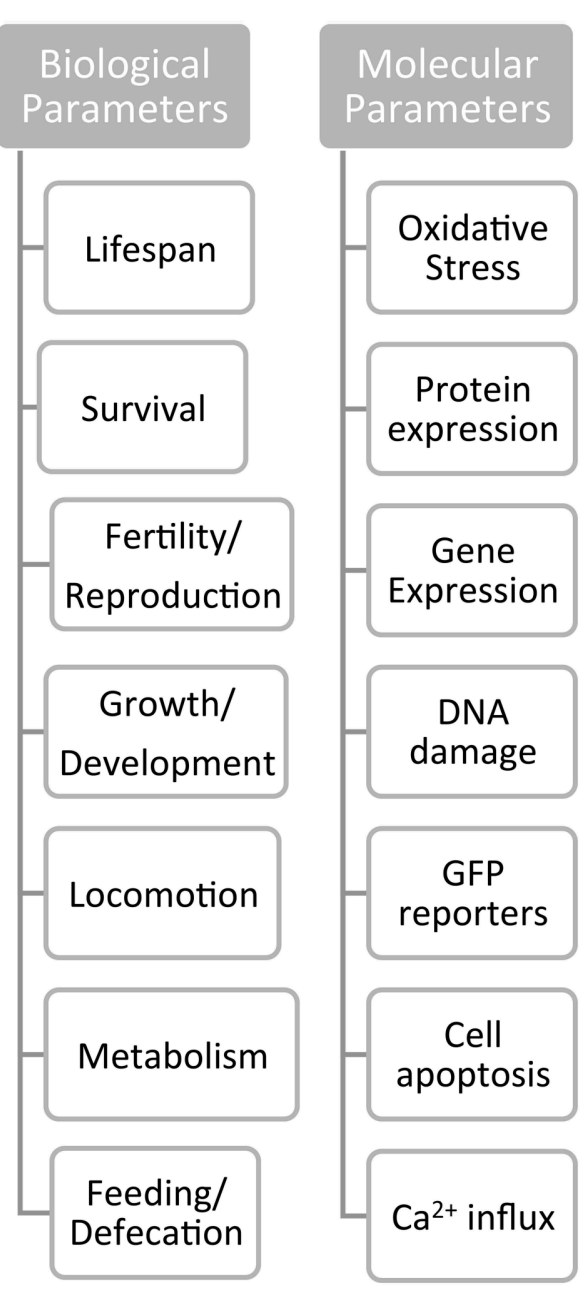

FIGURE 1 | Biological and molecular endpoints that can be assessed in C. elegans following exposure to nanomaterials.

cuticle absorbs very little. Regarding exposure time, worms can be exposed acutely (30 min, for example) or throughout their whole life.

Regarding NMs, the evaluation of their potential toxic effects has become necessary, as there is a growing concern on the short and long-terms effects following exposure. Among the available models, C. elegans characteristics advise for using this nematode as a living system for the primary screening of NMs toxicity (Gonzalez-Moragas et al., 2015). One of the most tested NMs is silver nanoparticles (AgNPs). In worms, treatment using sublethal concentrations of AgNPs could lead to neurotoxicity. Exposure to $100 \mathrm{mg} \mathrm{AgNPs} / \mathrm{L}$ reduced the velocity, flex, amplitude, and wavelength of the body bend of exposed worms, which was worsened in the progeny (Contreras et al., 2014). Of note, worms locomotion is regulated by gamma-aminobutyric acid-ergic (GABAergic), cholinergic and dopaminergic neurons, then alteration in these parameters may indicate neuronal damage (Jorgensen, 2005; Rand, 2007). Additionally, AgNP is reported to reduce survival and reproductivity in C. elegans, and also to cause severe edema after being in contact with the biological surfaces of the worm (Kim et al., 2012). 
The toxicity of titanium dioxide $\left(\mathrm{TiO}_{2}\right)$, zinc oxide, and silicon dioxide $\left(\mathrm{SiO}_{2}\right)$ nanoparticles (NPs) has been compared using different approaches such as, lethality, locomotion, growth, reproduction, and the production of reactive oxygen species $(\mathrm{Wu}$ et al., 2013). Particularly, $\mathrm{TiO}_{2}$ NPs led to a substantial decrease in both head thrash or body bend in superoxide dismutase (SOD)-2, SOD-3, metallothionein-2, and heat shock protein-16.48 mutants compared to the wild-type ( $\mathrm{Wu}$ et al., 2014). These findings suggest that the lack of SOD isoforms, metallothioneins, and heat shock proteins, which are proteins involved in oxidative stress protection and metal elimination, render worms more susceptible to these NPs. In an attempt to reduce NPs toxicity, polymeric coatings have been used to increase water solubility, to reduce toxicity and to direct site-specific metal delivery (Subbiah et al., 2010; Thanh and Green, 2010).

Long-term early onset exposure to Cadmium Telluride quantum dots (CdTe QD-0.1 and $1 \mu \mathrm{g} / \mathrm{L}$ ) caused abnormal foraging behavior, which is related to the altered function of the motor neurons (Zhao et al., 2015). In accordance, there was a decreased fluorescence of motor neurons cell bodies, indicating an alteration in their development. Furthermore, authors demonstrated that these CdTeQDs crossed the intestinal barrier and reached RME neurons, which are GABAergic motor neurons.

Regarding organic based NMs, hydroxylated fullerene NPs were reported being able to induce apoptosis in C. elegans (Cha et al., 2012). In fact, organic polymeric NPs toxicity assessment is still scarce in the literature. It has been demonstrated that melatonin-loaded-lipid core nanocapsules showed better antioxidant activity than free melatonin (Charão et al., 2015). Besides, a study with acute exposure to polysorbate coated polymeric nanocapsules loaded with clozapine showed that the nanoencapsulation reduced the toxicity of the antipsychotic (Sanches Moraes et al., 2016). However, this study demonstrated an acute toxicity of the formulation without the drug, which was not observed in a long-term manner. Notably, a recent study with nanopesticides showed that unloaded formulations have a strong toxic effect in worms, reducing survival, brood size, and delaying worms development (Jacques et al., 2017). By using fluorescent formulations, it was observed that they remained in the intestine of the worms, which may be the cause of the toxic effects.

\section{Enchytraeid Toxicity Studies: Enchytraeus crypticus/Enchytraeus albidus}

Enchytraeids are abundant soil organisms with worldwide distribution. They often live in the actual soil layer and provide important functions to the soil ecosystem, mostly indirectly, facilitating the organic matter turnover. They are sensitive to chemicals and stressors; hence the enchytraeid reproduction test (ERT), a chronic laboratory test for the testing of chemicals and soil quality assessment, was developed for E. albidus (Römbke and Moser, 2002). It has standard guidelines by ISO (ISO 16387, 2014) and OECD (OECD, 2016) where several test species can be used. E. crypticus has a shorter life cycle and is among the test species of choice in recent years. It has been given considerable focus and has currently an extensive suite of tools available for hazard assessment, far beyond the standard ecotoxicity test battery of many other species. The tools cover bioaccumulation (Amorim et al., 2011), avoidance (Bicho et al., 2015a), full life cycle test (Bicho et al., 2015b, 2016, 2017a; Santos et al., 2017), embryotoxicity (Gonçalves et al., 2015), full life span (Gonçalves et al., 2017), multigenerational (Bicho et al., 2017b), multispecies (mesocosm) system (SMS) (Menezes-Oliveira et al., 2013), full transcriptome and microarray tool (Castro-Ferreira et al., 2014; Gomes et al., 2017), oxidative stress biomarkers (Ribeiro et al., 2015), energy metabolism and cellular energy allocation (Gomes et al., 2015a), genotoxicity via the comet assay (Maria et al., 2017), and metabolomics and proteomics. This species has further potential as it can be exposed via water for a short period and hence allows the assessment of other routes of exposure (Gomes et al., 2015b).

An essential element of a systems toxicology approach is to have a broad combination of tools and endpoints being able to cover many levels of biological organization; therefore E. crypticus is an exquisite model at the moment. With this species, effects can be assessed by the transcriptome and metabolome, which can underpin mechanisms but also generate hypothesis for further testing. This is very important in an intelligent testing strategy context where efforts must be dedicated and prioritized. At the cellular level, various tools are optimized covering oxidative stress biomarkers, histology, embryo development, or cellular energy allocation. Organism level effects are broadly populated with results for avoidance behavior, survival, reproduction, and kinetics (bioaccumulation). More recently, a full life cycle test is also available, including hatching success, growth, and maturity besides survival and reproduction endpoints. This species has also an established procedure for a full life span test and multigenerational. The latter allows the assessment of epigenetic potential.

E. crypticus has been successfully used for assessing the effects of several NMs including silver, copper, nickel, $\mathrm{TiO}_{2}$, silica, iron oxide, tungsten carbide cobalt, multi-wall carbon nanotubes (MWCNTs), organic pigments, and nanopesticides. Adaptations to existing guidelines or developments of novel tools have been made. For example, the full life cycle test (46 days), an extension of the standard reproduction test (21 days), where effects could be discriminated between nano and non-nano form materials such as silver. Bicho and co-workers observed that embryo development, hatching, and survival of juveniles were less affected by silver nitrate than AgNPs (Ag NM300K) (Bicho et al., 2016). In this case study, it was clear that the standard guideline was too limited compared to the full life cycle test.

Concerning novel tools, the full life span test was developed considering the issues of long term testing and NMs persistency. As shown, exposure to copper oxide nanomaterials at the reproduction $\mathrm{EC}_{50}$ caused shorter longevity than exposure to copper-salt, bringing a novel concept to ecotoxicology (Gonçalves et al., 2017).

In sum, the tools are available and the potential for in-depth studies should be explored. Although, E. crypticus will not cover the effects of all terrestrial ecosystem and the use of different species is always recommended, preferably including differing life traits and taxonomic groups. 


\section{Mammalian Toxicity (Rodents)}

The ecological soil screening levels for mammals considered two potential exposure pathways to chemicals: incidental ingestion of contaminated soil, and ingestion of contaminated food items (EPA, 2007). Regarding NMs occupational safety, the importance of gastrointestinal tract is nil in comparison to respiratory airways. However, if the NMs are applied on food items the evaluation of oral toxicity become essential (Pachapur et al., 2015).

Oral and inhalation toxicity studies should be performed in at least one mammalian species. Following OECD TG, rats are the preferred rodent species for the studies unless a species more representative of human toxicity is known. Rodents have been preferred due to their extensive use in pharmacological and toxicological studies, relatively short life cycle, susceptibility to tumor induction, and availability of characterized strains. Consequently, their physiology and pathology characteristics have been well-documented in several studies.

To test acute oral and inhalation toxicity, there are four OECD TG (420, 423, 425, and 403) and two US Environmental Protection Agency (EPA) TG (OPPTS 870.1100, 870.1300). In these guidelines, female rats are normally used as their Lethal dose (LD50)-value is slightly lower than in males indicating a higher sensitivity. However, if males could be more susceptible to the test compound, then males or both sexes should be used. Following the single treatment using the test compound, animals should be observed daily for mortality, body weight changes, and clinical signs of toxicity including alterations in behavior patterns and physiological functions that indicated an abnormal function of circulatory, respiratory, autonomic, and central nervous systems. After 14 days, the animals should be sacrificed, and pathological changes evaluated (EPA, 1998a, 2002; OECD, 2002a,b; OECD, 2008b, 2009b).

Additionally, sub-chronic and chronic toxicity studies should be performed to determine the toxicological profile of the new compound after repeated oral (OECD TG 407, 408; OPPTS $870.3050,870.3100$ ) or inhalation exposure (OECD TG 412, 413; OPPTS 870.3465). These studies provide detailed information about the potential target organs of toxicity, the exposureresponse relationships, as well as the potential reversibility of the toxic effects (EPA, 1998b,c, 2000; OECD, 1998, 2008a, 2009c,d). Furthermore, significant data on nervous, immune, endocrine, and reproductive systems can also be obtained even specific guidelines are available to investigate these endpoints. Table 1 summarizes the OECD guidelines for acute and repeated dose toxicity studies.

In a 28-day rat oral toxicity study, the effects of $1,000 \mathrm{mg} / \mathrm{kg}$ bw/day of barium sulfate, two surface-functionalized zirconium dioxide, and four amorphous $\mathrm{SiO}_{2} \mathrm{NPs}$ with or without surface functionalization were evaluated according to OECD TG 407. None of the tested nanomaterials cause local or systemic effects (Buesen et al., 2014). Similarly, studies performed by Matsumoto and co-workers did not reveal toxic effects after acute and

TABLE 1 | OECD guidelines for acute and repeated toxicity studies.

\begin{tabular}{|c|c|c|c|c|}
\hline Guideline $\mathbf{n}^{\circ}$ & Guideline title & Duration & Species/Sex & Principal endpoints \\
\hline OECD 220 & Enchytraeid reproduction test & 42 days & Enchytraeus albidus & $\begin{array}{l}\text { Mortality; Reproduction; Median Lethal } \\
\text { Concentration (LC50); Median Effective } \\
\text { Concentration (EC50); No Observed Effect } \\
\text { Concentration (NOEC) and/or Effective } \\
\text { Concentration (ECx) }\end{array}$ \\
\hline $\begin{array}{l}\text { OECD } 420 \\
\text { OECD } 423 \\
\text { OECD } 425\end{array}$ & $\begin{array}{l}\text { Acute oral toxicity - fixed dose procedure } \\
\text { Acute oral toxicity - acute toxic class method } \\
\text { Acute oral toxicity: up-and-down procedure }\end{array}$ & $\begin{array}{l}14 \text { days } \\
\text { (single dose) }\end{array}$ & Rats/Normally females & $\begin{array}{l}\text { Clinical signs of toxicity; body weight } \\
\text { changes; gross necropsy; histopathological } \\
\text { examination*; LD50 }\end{array}$ \\
\hline OECD 407 & Repeated dose 28-day oral toxicity study in rodents & 28 days (daily dose) & Rodents (rat & Clinical signs of toxicity; body weight and \\
\hline OECD 408 & Repeated dose 90-day oral toxicity study in rodents & 90 days (daily dose) & $\begin{array}{l}\text { preferably)/Males and } \\
\text { females }\end{array}$ & $\begin{array}{l}\text { food/water consumption; hematology and } \\
\text { clinical biochemistry; gross necropsy/organs } \\
\text { weight; full histopathological examination. }\end{array}$ \\
\hline OECD 403 & Acute inhalation toxicity & $\begin{array}{l}14 \text { days (One exposure } \\
\text { session) Traditional: fixed } \\
\text { period of time (up to } 6 \mathrm{~h} \text { ); } \\
\text { Nose- or whole body-only } \\
\mathrm{C} \text { x t: multiple time } \\
\text { durations; Nose-only }\end{array}$ & $\begin{array}{l}\text { Rat } \\
\text { preferably/Susceptible } \\
\text { sex. }\end{array}$ & $\begin{array}{l}\text { Clinical signs of toxicity; body weight } \\
\text { changes; gross necropsy; lung weight; } \\
\text { microscopic examination of the entire } \\
\text { respiratory tract; histopathological } \\
\text { examination* }\end{array}$ \\
\hline OECD 412 & Subacute inhalation toxicity: 28-day study & $\begin{array}{l}28 \text { days ( } 6 \text { h/daily exposure } \\
\text { session) }\end{array}$ & $\begin{array}{l}\text { Rodents/Males and } \\
\text { females }\end{array}$ & $\begin{array}{l}\text { Clinical signs of toxicity; body weight } \\
\text { changes; hematology and clinical } \\
\text { biochemistry; gross necropsy/organs } \\
\text { weight; full histopathological examination. }\end{array}$ \\
\hline OECD 413 & Subchronic inhalation toxicity: $90-$ day Study & $\begin{array}{l}90 \text { days ( } 6 \text { h/daily exposure } \\
\text { session) }\end{array}$ & $\begin{array}{l}\text { Preferred species are } \\
\text { rats/Males and females }\end{array}$ & $\begin{array}{l}\text { Clinical signs of toxicity; body weight } \\
\text { changes; hematology and clinical } \\
\text { biochemistry; gross necropsy/organs } \\
\text { weight; full histopathological examination. }\end{array}$ \\
\hline
\end{tabular}

${ }^{*}$ Microscopic examination of organs showing evidence of gross pathology in animals surviving 24 or more hours, and organs known or expected to be affected.C $\times t$, Concentration $\times$ Time protocol. 
repeated oral doses of single- or multi-wall carbon nanotubes (Matsumoto et al., 2012).

The toxicity of MWCNTs is more adverse in the case of inhalation as compared to oral exposure. Rats exposed to 2.5 $\mathrm{mg} / \mathrm{m}^{3}$ MWCNTs for $6 \mathrm{~h} /$ day during 5 consecutive days using a head-nose system demonstrated signs of pulmonary toxicity such as, microgranulomas and diffuse alveolar histiocytosis (Ma-Hock et al., 2013). After a 13-week exposure period, the inhalation of $2.5 \mathrm{mg} / \mathrm{m}^{3}$ MWCNTs induced systemic inflammation and histopathological abnormalities in the lungs, lymph nodes, nasal cavity, larynx, and trachea (Ma-Hock et al., 2009).

The inhalation models performed in rats have some limitations, and it is important to consider the interspecies differences in physiology. Animal models exhibited differences in the breathing pattern when compared to humans however they can provide evidence on the fate of inhaled nanomaterials and their biological interactions (Fröhlich and Salar-behzadi, 2014).

\section{CONCLUSIONS}

The exponential growth of nanomaterials has broad ecotoxicological implications because of their potential impacts on the environment. The use of internationally accepted test guidelines helps to improve the reproducibility, reliability,

\section{REFERENCES}

Amorim, M. J., Oliveira, E., Teixeira, A. S., Gravato, C. S., Loureiro, S., Guilhermino, L. C., et al. (2011). Toxicity and bioaccumulation of phenanthrene in Enchytraeus albidus (Oligochaeta: Enchytraeidae). Environ. Toxicol. Chem. 30, 967-972. doi: 10.1002/etc.464

Amorim, M. J., Roca, C. P., and Scott-Fordsmand, J. J. (2016). Effect assessment of engineered nanoparticles in solid media - current insight and the way forward. Environ. Pollut. 218, 1370-1375. doi: 10.1016/j.envpol.2015.08.048

Bicho, R. C., Gomes, S. I., Soares, A. M., and Amorim, M. J. (2015a). Non-avoidance behaviour in enchytraeids to boric acid is related to the GABAergic mechanism. Environ. Sci. Pollut. Res. 22, 6898-6903. doi: 10.1007/s11356-014-3921-5

Bicho, R. C., Ribeiro, T., Rodrigues, N. P., Scott-Fordsmand, J. J., and Amorim, M. J. (2016). Effects of Ag nanomaterials (NM300K) and $\mathrm{Ag}$ salt $\left(\mathrm{AgNO}_{3}\right)$ can be discriminated in a full life cycle long term test with Enchytraeus crypticus. J. Hazard. Mater. 318, 608-614. doi: 10.1016/j.jhazmat.2016.07.040

Bicho, R. C., Santos, F. C. F., Scott-Fordsmand, J. J., and Amorim, M. J. (2017a). Effects of copper oxide nanomaterials (CuONMs) are life stage dependent - full life cycle in Enchytraeus crypticus. Environ. Pollut. 224, 117-124. doi: 10.1016/j.envpol.2017.01.067

Bicho, R. C., Santos, F. C. F., Scott-Fordsmand, J. J., and Amorim, M. J. B. (2017b). Multigenerational effects of copper nanomaterials (CuONMs) are different of those of $\mathrm{CuCl}_{2}$ : exposure in the soil invertebrate Enchytraeus crypticus. Sci Rep. 7:8457. doi: 10.1038/s41598-017-08911-0

Bicho, R. C., Santos, F. C., Gonçalves, M. F., Soares, A. M., and Amorim, M. J. (2015b). Enchytraeid reproduction test ${ }^{\text {PLUS }}$ : hatching, growth and full life cycle test - an optional multi-endpoint test with Enchytraeus crypticus. Ecotoxicology 24, 1053-1063. doi: 10.1007/s10646-015-1445-5

Brenner, S. (1974). The genetics of Caenorhabditis elegans. Genetics 77, 71-94.

Buesen, R., Landsiedel, R., Sauer, U. G., Wohlleben, W., Groeters, S., and Strauss, V. (2014). Effects of $\mathrm{SiO}_{2}, \mathrm{ZrO}_{2}$, and $\mathrm{BaSO}_{4}$ nanomaterials with or without surface functionalization upon 28-day oral exposure to rats. Arch. Toxicol. 88, 1881-1906. doi: 10.1007/s00204-014-1337-0

Castro-Ferreira, M. P., de Boer, T. E., Colbourne, J. K., Vooijs, R., van Gestel, C. A. M., van Straalen, N. M., et al. (2014). Transcriptome assembly and microarray construction for Enchytraeus crypticus, a model oligochaete to assess stress response mechanisms derived from soil conditions. BMC Genomics 15:302. doi: 10.1186/1471-2164-15-302 and data quality of the studies and contribute to support a common regulatory framework. Herein, we summarize some of the current test guidelines and the understanding of NMs toxicity to terrestrial representative species of various trophic levels, including E. crypticus/E. albidus, C. elegans, and rodents. Combining observations assessed on organisms from different phyla and using different methodologies allows for more accurate environmental monitoring and is recommended.

\section{AUTHOR CONTRIBUTIONS}

DÁ wrote the section "Nematode toxicity studies: Caenorhabditis elegans". MA wrote the section "Enchytraeid Toxicity Studies: Enchytraeus crypticus/Enchytraeus albidus". MM and CR wrote the section "Mammalian Toxicity (Rodents)". MdJ conceived the idea and reviewed the manuscript text. All authors read and approved the final manuscript.

\section{ACKNOWLEDGMENTS}

This work was supported by the São Paulo Research Foundation (FAPESP; grant \#2014/03002-7 and \#2016/03765-6) and National Council for Scientific and Technological Development (CNPq; grant \#453963/2014-5).

C. elegans Sequencing Consortium (1998). Genome sequence of the nematode $C$. elegans: a platform for investigating biology. Science 282, 2012-2018.

Cha, Y. J., Lee, J., and Choi, S. S. (2012). Apoptosis-mediated in vivo toxicity of hydroxylated fullerene nanoparticles in soil nematode Caenorhabditis elegans. Chemosphere 87, 49-54. doi: 10.1016/j.chemosphere.2011.11.054

Chalfie, M., Tu, Y., Euskirchen, G., Ward, W., and Prasher, D. (1994). Green fluorescent protein as a marker for gene expression. Science 263, 802-805. doi: 10.1126/science.8303295

Charão, M. F., Souto, C., Brucker, N., Barth, A., Jornada, D. S., Fagundez, D., et al. (2015). Caenorhabditis elegans as an alternative in vivo model to determine oral uptake, nanotoxicity, and efficacy of melatonin-loaded lipid-core nanocapsules on paraquat damage. Int. J. Nanomed. 10, 5093-5106. doi: 10.2147/IJN.S84909

Contreras, E. Q., Puppala, H. L., Escalera, G., Zhong, W., and Colvin, V. L. (2014). Size-dependent impacts of silver nanoparticles on the lifespan, fertility, growth, and locomotion of Caenorhabditis elegans. Environ. Toxicol. Chem. 33, 2716-2723. doi: 10.1002/etc. 2705

ECHA (2014). "Human health and environmental exposure assessment and risk characterisation of nanomaterials," in Best Practice for REACH Registrants, Third GAARN meeting (Helsinki).

El Badawy, A. M., Luxton, T. P., Silva, R. G., Scheckel, K. G., Suidan, M. T., and Tolaymat, T. M. (2010). Impact of environmental conditions ( $\mathrm{pH}$, ionic strength, and electrolyte type) on the surface charge and aggregation of silver nanoparticles suspensions. Environ. Sci. Technol. 44, 1260-1266. doi: $10.1021 / \mathrm{es} 902240 \mathrm{k}$

EPA (1998a). Health Effects Test Guidelines. OPPTS 870.1300 Acute Inhalation Toxicity.

EPA (1998b). Health Effects Test Guidelines. OPPTS 870.3100-90-Day Oral Toxicity in Rodents.

EPA (1998c). Health Effects Test Guidelines. OPPTS 870.3465-90-Day Inhalation Toxicity.

EPA (2000). Health Effects Test Guidelines. OPPTS 870.3050 Repeated Dose 28Day Oral Toxicity Study in Rodents.

EPA (2002). Health Effects Test Guidelines. OPPTS 870.1100 Acute Oral Toxicity. EPA (2007). Guidance for Developing Ecological Soil Screening Levels (Eco-SSLs).

Fröhlich, E., and Salar-behzadi, S. (2014). Toxicological assessment of inhaled nanoparticles: role of in vivo, ex vivo, in vitro, and in silico studies. Int. J. Mol. Sci. 15, 4795-4822. doi: 10.3390/ijms15034795 
Gomes, S. I. L., Caputo, G., Pinna, N., Scott-Fordsmand, J. J., and Amorim, M. J. B. (2015a). Effect of 10 different $\mathrm{TiO}_{2}$ and $\mathrm{ZrO}_{2}$ (nano)materials on the soil invertebrate Enchytraeus crypticus. Environ. Toxicol. Chem. 34, 2409-2416. doi: 10.1002/etc.3080

Gomes, S. I. L., Roca, C. P., Scott-Fordsmand, J. J., Amorim, M. J. B., Aruoja, V., Suppi, S., et al. (2017). High-throughput transcriptomics reveals uniquely affected pathways: AgNPs, PVP-coated AgNPs and Ag NM300K case studies. Environ. Sci. Nano 4, 929-937. doi: 10.1039/C6EN00652C

Gomes, S. I. L., Scott-Fordsmand, J. J., Amorim, M. J. B., Tchounwou, P. B., and Toscano, W. A. (2015b). Cellular energy allocation to assess the impact of nanomaterials on soil invertebrates (Enchytraeids): the effect of $\mathrm{Cu}$ and Ag. Int. J. Environ. Res. Public Health 12, 6858-6878. doi: 10.3390/ijerph120606858

Gonçalves, M. F. M., Gomes, S. I. L., Scott-Fordsmand, J. J., and Amorim, M. J. B. (2017). Shorter lifetime of a soil invertebrate species when exposed to copper oxide nanoparticles in a full lifespan exposure test. Sci. Rep. 7:1355. doi: 10.1038/s41598-017-01507-8

Gonçalves, M. F., Bicho, R. C., Rêma, A., Soares, A. M., Faustino, A. M., and Amorim, M. J. (2015). Development of an embryotoxicity test for Enchytraeus crypticus-the effect of Cd. Chemosphere 139, 386-392. doi: 10.1016/j.chemosphere.2015.07.021

Gonzalez-Moragas, L., Roig, A., and Laromaine, A. (2015). C. elegans as a tool for in vivo nanoparticle assessment. Adv. Colloid Interface Sci. 219, 10-26. doi: 10.1016/j.cis.2015.02.001

Grillo, R., Rosa, A. H., and Fraceto, L. F. (2015). Engineered nanoparticles and organic matter: a review of the state-of-the-art. Chemosphere 119, 608-619. doi: 10.1016/j.chemosphere.2014.07.049

Holden, P. A., Gardea-Torresdey, J. L., Klaessig, F., Turco, R. F., Mortimer, M., Hund-Rinke, K., et al. (2016). Considerations of environmentally relevant test conditions for improved evaluation of ecological hazards of engineered nanomaterials. Environ. Sci. Technol. 50, 6124-6145. doi: 10.1021/acs.est.6b00608

ISO 16387 (2014). Soil Quality-Effects of Contaminants on Enchytraeidae (Enchytraeus sp.)-Determination of Effects on Reproduction. Geneva: ISO Publishing.

ISO/TS 80004-1 (2015). Nanotechnologies-Vocabulary-Part 1: Core Terms. Geneva: ISO Publishing.

Jacques, M. T., Oliveira, J. L., Campos, E. V., Fraceto, L. F., and Ávila, D. S. (2017). Safety assessment of nanopesticides using the roundworm Caenorhabditis elegans. Ecotoxicol. Environ. Saf. 139, 245-253. doi: 10.1016/j.ecoenv.2017.01.045

Jorgensen, E. M. (2005). Gaba. WormBook 1, 1-13. doi: 10.1895/wormbook.1.14.1

Kim, S. W., Nam, S. H., and An, Y. J. (2012). Interaction of silver nanoparticles with biological surfaces of Caenorhabditis elegans. Ecotoxicol. Environ. Saf. 77, 64-70. doi: 10.1016/j.ecoenv.2011.10.023

Ma-Hock, L., Strauss, V., Treumann, S., Küttler, K., Wohlleben, W., Hofmann, T., et al. (2013). Comparative inhalation toxicity of multi-wall carbon nanotubes, graphene, graphite nanoplatelets and low surface carbon black. Part. Fibre Toxicol. 10:23. doi: 10.1186/1743-8977-10-23

Ma-Hock, L., Treumann, S., Strauss, V., Brill, S., Luizi, F., Mertler, M., et al. (2009). Inhalation toxicity of multiwall carbon nanotubes in rats exposed for 3 months. Toxicol. Sci. 112, 468-481. doi: 10.1093/toxsci/kfp146

Maria, V. L., Ribeiro, M. J., Guilherme, S. M., Soares, A. M. V., Scott-Fordsmand, J. J., and Amorim, M. J. B. (2017). Silver (nano)materials cause genotoxicity in Enchytraeus crypticus-as determined by the comet assay. Environ. Toxicol. Chem. doi: 10.1002/etc.3944. [Epub ahead of print].

Matsumoto, M., Serizawa, H., Sunaga, M., Kato, H., and Takahashi, M. (2012). No toxicological effects on acute and repeated oral gavage doses of single-wall or multi-wall carbon nanotube in rats. 37, 463-474. doi: 10.2131/jts.37.463

Menezes-Oliveira, V. B., Scott-Fordsmand, J. J., Soares, A. M., and Amorim, M. J. (2013). Effects of temperature and copper pollution on soil communityextreme temperature events can lead to community extinction. Environ. Toxicol. Chem. 32, 2678-2685. doi: 10.1002/etc. 2345

OECD (1998). Test No. 408: Repeated Dose 90-day Oral Toxicity Study in Rodents. Paris: OECD Publishing.

OECD (2002a). Test No. 420: Acute Oral Toxicity - Fixed Dose Procedure. Paris: OECD Publishing.

OECD (2002b). Test No. 423: Acute Oral toxicity - Acute Toxic Class Method. Paris: OECD Publishing.

OECD (2008a). Test No. 407: Repeated Dose 28-day Oral Toxicity Study in Rodents. Paris: OECD Publishing.

OECD (2008b). Test No. 425: Acute Oral Toxicity: Up-and-Down Procedure. Paris: OECD Publishing.
OECD (2009a). Preliminary Review of OECD Test Guidelines for their Applicability to Manufactured Nanomaterials. Paris: OECD Publishing.

OECD (2009b). Test No. 403: Acute Inhalation Toxicity. Paris: OECD Publishing.

OECD (2009c). Test No. 412: Subacute Inhalation Toxicity: 28-Day Study. Paris: OECD Publishing.

OECD (2009d). Test No. 413: Subchronic Inhalation Toxicity: 90-day Study. Paris: OECD Publishing.

OECD (2016). Test No. 220: Enchytraeid Reproduction Test. Paris: OECD Publishing.

Pachapur, V., Brar, S. K., Verma, M., and Surampalli, R. Y. (2015). "Nano-ecotoxicology of natural and engineered nanomaterials for animals and humans," in Nanomaterials in the Environment, 421-437. doi: 10.1061/9780784414088.ch16

Rand, J. (2007). “Acetylcholine,” in WormBook, 1-21. doi: 10.1895/wormbook. 1.131 .1

Rasmussen, K., González, M., Kearns, P., Sintes, J. R., Rossi, F., and Sayre, P. (2016). Review of achievements of the OECD working party on manufactured nanomaterials' testing and assessment programme. From exploratory testing to test guidelines. Regul. Toxicol. Pharmacol. 74, 147-160. doi: 10.1016/j.yrtph.2015.11.004

Ribeiro, M. J., Maria, V. L., Scott-Fordsmand, J. J., and Amorim, M. J. (2015). Oxidative stress mechanisms caused by Ag nanoparticles (NM300K) are different from those of $\mathrm{AgNO}_{3}$ : effects in the soil invertebrate Enchytraeus Crypticus. Int. J. Environ. Res. Public Health 12, 9589-9602. doi: 10.3390/ijerph120809589

Römbke, J., and Moser, T. (2002). Validating the enchytraeid reproduction test: organisation and results of an international ringtest. Chemosphere 46, 1117-1140. doi: 10.1016/S0045-6535(01)00113-8

Sanches Moraes, B. K., Vieira, S. M., Salgueiro, W. G., Michels, L. R., Colomé, L. M., Avila, D. S., et al. (2016). Clozapine-loaded polysorbatecoated polymeric nanocapsules: physico-chemical characterization and toxicity evaluation in Caenorhabditis elegans model. J. Nanosci. Nanotechnol. 16, 1257-1264. doi: 10.1166/jnn.2016.11668

Santos, F. C. F., Gomes, S. I. L., Scott-Fordsmand, J. J., and Amorim, M. J. B. (2017) Hazard assessment of nickel nanoparticles in soil-the use of a full life cycle test with Enchytraeus crypticus. Environ. Toxicol. Chem. doi: 10.1002/etc.3853. [Epub ahead of print].

Subbiah, R., Veerapandian, M., and Yun, K. S. (2010). Nanoparticles: functionalization and multifunctional applications in biomedical sciences. Curr. Med. Chem. 17, 4559-4577. doi: 10.2174/092986710794183024

Sulston, J. E., Schierenberg, E., White, J. G., and Thomson, J. N. (1983). The embryonic cell lineage of the nematode Caenorhabditis elegans. Dev. Biol. 100, 64-119. doi: 10.1016/0012-1606(83)90201-4

Thanh, N. T. K., and Green, L. A. W. (2010). Functionalisation of nanoparticles for biomedical applications. Nano Today 5, 213-230. doi: 10.1016/j.nantod.2010.05.003

Wu, Q., Nouara, A., Li, Y., Zhang, M., Wang, W., Tang, M., et al. (2013). Comparison of toxicities from three metal oxide nanoparticles at environmental relevant concentrations in nematode Caenorhabditis elegans. Chemosphere 90, 1123-1131. doi: 10.1016/j.chemosphere.2012.09.019

Wu, Q., Zhao, Y., Li, Y., and Wang, D. (2014). Susceptible genes regulate the adverse effects of $\mathrm{TiO}_{2}$-NPs at predicted environmental relevant concentrations on nematode Caenorhabditis elegans. Nanomed. Nanotechnol. Biol. Med. 10, 1263-1271. doi: 10.1016/j.nano.2014.03.010

Zhao, Y., Wang, X., Wu, Q., Li, Y., and Wang, D. (2015). Translocation and neurotoxicity of CdTe quantum dots in RMEs motor neurons in nematode Caenorhabditis elegans. J. Hazard. Mater. 283, 480-489. doi: 10.1016/j.jhazmat.2014.09.063

Conflict of Interest Statement: The authors declare that the research was conducted in the absence of any commercial or financial relationships that could be construed as a potential conflict of interest.

Copyright (c) 2017 Mendonça, Rizoli, Ávila, Amorim and de Jesus. This is an openaccess article distributed under the terms of the Creative Commons Attribution License (CC BY). The use, distribution or reproduction in other forums is permitted, provided the original author(s) or licensor are credited and that the original publication in this journal is cited, in accordance with accepted academic practice. No use, distribution or reproduction is permitted which does not comply with these terms. 